\title{
Non-additive thermally treated municipal solid waste incineration (MSWI) fly-ash and its utilization as supplementary cementitious materials
}

\author{
J. A. Siddique ${ }^{1}$, M. Keppert ${ }^{2}$, K. Polozhiy ${ }^{2} \&$ R. Černý ${ }^{1}$ \\ ${ }^{1}$ Department of Materials Engineering and Chemistry, \\ Faculty of Civil Engineering, Czech Technical University in Prague, \\ Czech Republic \\ ${ }^{2}$ University Center for Energy Efficient Buildings, \\ Czech Technical University in Prague, Czech Republic
}

\begin{abstract}
Municipal solid waste incineration (MSWI) fly ash is considered as hazardous waste having its own high concentration of heavy metals, inorganic salts and the presence of chlorinated organic compounds, such as PCDD/F. The aim of this study was to minimize the hazardous chemicals and heavy metals to usefully apply MSWI fly ash as a Supplementary Cementitious Material (SCM). Here in this work we apply non additive thermal treatment of MSWI fly ash up to $1000^{\circ} \mathrm{C}$ temperature. The physical and chemical characteristics of MSWI fly ash were first analyzed to introduce them into the concrete. A quantitative mineralogical composition of the ash was determined. The performance characteristics (setting times, compressive strengths) for mortars containing treated ash were studied. These promising results indicate that non additive thermal treatment process is quite effective and reliable for recycling of MSWI fly ashes.
\end{abstract}

Keywords: MSWI fly ash, SCM, heavy metals, non-additive thermal treatment.

\section{Introduction}

Municipal solid waste incineration (MSWI) is a most accepted technique for waste management [1], plays a significant role in reduction of waste volume and 
weight combined along with the thermal energy production [2]. Therefore, incineration considered a better option than the land filling [3]. However, the ash generates during incineration effects major environmental affairs, since it consist of a large number oxides $\left(\mathrm{SiO}_{2}, \mathrm{Al}_{2} \mathrm{O}_{3}, \mathrm{Fe}_{2} \mathrm{O}_{3}, \mathrm{CaO}, \mathrm{MgO}\right)$ and alkalies $\left(\mathrm{Na}_{2} \mathrm{O}\right.$, $\mathrm{K}_{2} \mathrm{O}$ ) the MSWI ashes contain higher amount of trace elements, especially heavy metals, dioxins and soluble salts [4]. Therefore, suitable and constructive ways for the fly ash (FA) disposal are extremely required [5]. Since July 2002 [6], European landfills are not allowed to receive such waste without pre-treatments have been applied. Around the world researchers are more concern on safe disposal of MSWI bottom and fly ash [7] and its application mainly for recycling into construction materials [8].

There are different treatments and approaches have been developed by the scientific research community can be grouped into three major classes; 1) separation processes: introduce all the techniques like washing [9], thermal [10] and electrochemical processes [11] that includes both to recover these components and to improve the quality for further utilization; 2) solidification/ stabilization ( $\mathrm{S} / \mathrm{S})$ processes: use binders or additives [12], soluble phosphates [13], ferrous iron sulphate [14] and carbonates in order to physically and chemically immobilize hazardous components; 3 ) thermal methods; like melting, [15], sintering, [16], vitrification [17], Plasma, [15] and Microwave, [18]. Researchers also have done much work on utilization to MSWI fly ash such as a component for ceramic product [19] as a raw material for Portland clinker production [20] in pavement asphalt [21] or glass-ceramics [22], polymer production [23] and many more. Supplementary cementitious material (SCM) in concrete admixture is also a method to utilize the MSWI generated fly ash and found most popular utilization in amongst.

There are three potential approaches available to utilize municipal solid waste incineration MSWI-FA as SCM, 1) Use as pozzolanic material; 2) Use as retardant ingredient; 3) Replacement of cement in concrete. However, replacement of Portland cement in concrete is more applicable in terms of lower water demand for similar workability, lower evolution of heat and reduced bleeding. Addition of FA is also helpful in reduces the cost of construction and increases its durability with the improvement of workability without compromising strength. Despite such promising results, only few works have been done to utilization of MSWI-FA as SCM due to presence of high concentration heavy metals and chlorides, involves risks of unacceptable delay of cement setting and considered as prime reason to affect their reuse. None of the techniques discuss above provide a final solution for the stabilization of heavy metals in fly ash.

In the present work, we are continuing our previous research on applying thermal treatment without use of any additives on incinerator acid washed (FAIW) and laboratory water washed fly-ash (FA-WW) to improve its quality by reducing content of the heavy metals and inorganic salts and utilization of FA as SCM in concrete. Primarily the ashes were collected from a MSWI facility in Czech Republic. Effect of thermal treatment (up to $1000^{\circ} \mathrm{C}$ ) on ashes' properties 
was studied and treated ashes were used as partial Portland cement replacement in mortars.

\section{Materials and method}

Three different MSWI fly ashes were studied. 1) Primary fly ash, used as collected in APC system of incinerator and without any treatment (FA-UT); it is mixture of ashes collected from boiler and electrostatic precipitator (ESP). 2) Thermally treated ash based on industrially (in MSWI facility) acid washed FA (donated by FA-IW-TT). 3) Thermally treated ash FA-UT was firstly water washed in laboratory conditions (agitated vessel, L/S (liquid/solid) $=10$ ) and then thermally treated (FA-WW-TT). Alumina crucible has been used to perform this non-additive thermal treatment. In the first step of treatment FA was dried to remove all water content at $105^{\circ} \mathrm{C}$ for $24 \mathrm{hrs}$ in electric laboratory furnace. In further step of thermal treatment heating was applied up to the $1000^{\circ} \mathrm{C}$ with the rate of $2^{\circ} \mathrm{C} / \mathrm{min}$ and collect the sample after every $200^{\circ} \mathrm{C}$ to observe the chemical composition and heavy metals quantity. The chemical composition and heavy metal content of ashes was checked by XRF (Thermo, ARL 9400 XP). The particle size distribution was also determined by laser diffraction analyser (Fritsch, Analysette 22 MicroTec plus) in ethanol in order to prevent possible hydration processes. Thermal analysis of ashes priory the bulk calcination was performed by help of Setaram calorimeter Labsys Evo under inert atmosphere from ambient temperature to $1000^{\circ} \mathrm{C}$. The untreated and treated ashes were applied as partial substitution of ordinary Portland cement in mortars (OPC; CEM I $42.5 \mathrm{R})$ (Table 1). The specimens of mortars (160x40x40 mm prisms) were stored at $100 \% \mathrm{RH}$ for 28 days and then its bending and compressive strength was measured (EN 196-1). The influence of ashes on initial and final setting time of standard consistency cement paste was evaluated by Vicat apparatus (EN 196-3).

Table 1: $\quad$ Composition of mortars.

\begin{tabular}{|c|c|c|c|c|}
\hline \multirow{2}{*}{} & OPC & Fly ash & Sand & \multirow{2}{*}{ w/b } \\
\cline { 2 - 3 } & \multicolumn{3}{|c|}{$\mathrm{kg} / \mathrm{m}^{3}$} & \\
\hline Control & 450 & - & 1650 & 0.55 \\
\hline $10 \%$ & 405 & 45 & 1650 & 0.55 \\
\hline $20 \%$ & 360 & 90 & 1650 & 0.55 \\
\hline $30 \%$ & 315 & 135 & 1650 & 0.55 \\
\hline
\end{tabular}

\section{Results and discussion}

As raw materials for thermal treatment were used two washed ashes FA-IW and FA-WW, both being products of FA-UT processing. Such water-based processing is insufficient mainly with respect to its unsatisfactory ability to reduce sulfates content which is rather high in FA-UT ash (Table 2). Thermogravimetry of FA-IW and FA-WW (Fig. 1) indicated its sensitivity to heat 


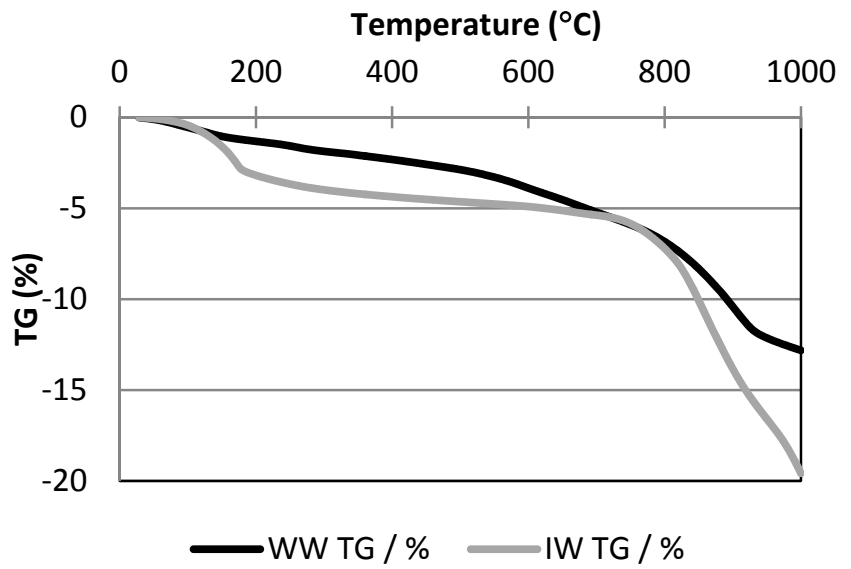

Figure 1: Thermogravimetry of ashes subjected to thermal treatment.

Table 2: $\quad$ Chemical composition of thermally treated fly ashes (wt. \%).

\begin{tabular}{|c|c|c|c|c|c|c|c|c|c|c|c|}
\hline & FA-UT & \multicolumn{5}{|c|}{ FA-IW-TT } & \multicolumn{5}{c|}{ FA-WW-TT } \\
\hline & & \multicolumn{5}{|c|}{ Temp. $\left({ }^{\circ} \mathrm{C}\right)$} & \multicolumn{5}{c|}{ Temp. } \\
\hline & & 200 & 400 & 600 & 800 & 1000 & 200 & 400 & 600 & 800 & 1000 \\
\hline $\mathrm{SiO}_{2}$ & 15.6 & 12.8 & 13.1 & 11.9 & 12 & 22.5 & 18.7 & 18.9 & 18.5 & 22.8 & 26.7 \\
\hline $\mathrm{Al}_{2} \mathrm{O}_{3}$ & 9.2 & 8.1 & 8.2 & 7.4 & 7.0 & 12.8 & 11.7 & 11.8 & 11.7 & 13.9 & 15.2 \\
\hline $\mathrm{Fe}_{2} \mathrm{O}_{3}$ & 2.6 & 2.4 & 2.5 & 2.3 & 2.4 & 3.3 & 3.0 & 2.9 & 2.9 & 3.1 & 3.5 \\
\hline $\mathrm{CaO}$ & 23.9 & 30.8 & 30.3 & 31.1 & 31.8 & 37.0 & 29.9 & 29.7 & 29.8 & 30.7 & 33.6 \\
\hline $\mathrm{MgO}$ & 1.8 & 1.1 & 1.1 & 1.1 & 1.1 & 2.3 & 2.4 & 2.5 & 2.5 & 3.5 & 3.4 \\
\hline $\mathrm{Na}_{2} \mathrm{O}$ & 9.4 & 0.6 & 0.8 & 0.8 & 0.7 & 1.1 & 2.9 & 2.9 & 3.3 & 2.0 & 2.2 \\
\hline $\mathrm{K}_{2} \mathrm{O}$ & 6.6 & 1.0 & 1.0 & 0.9 & 0.8 & 0.7 & 2.8 & 2.7 & 2.8 & 1.7 & 1.1 \\
\hline $\mathrm{Cl}$ & 11.2 & 0.4 & 0.3 & 0.2 & $\mathrm{BDL}$ & $\mathrm{BDL}$ & 3.1 & 3.1 & 3.3 & 0.1 & 0.0 \\
\hline $\mathrm{SO}_{3}$ & 11.5 & 36.6 & 36.1 & 38.1 & 37.8 & 11.2 & 13.8 & 13.9 & 13.7 & 10.7 & 2.1 \\
\hline $\mathrm{P}_{2} \mathrm{O}_{5}$ & 1.3 & 1.1 & 1.1 & 1.0 & 1.0 & 1.9 & 1.7 & 1.7 & 1.7 & 2.2 & 2.4 \\
\hline
\end{tabular}

treatment, where at lower temperatures (to $200^{\circ} \mathrm{C}$ ) gypsum and basanite decompose to anhydrite while at temperature above $800^{\circ} \mathrm{C}$ also calcite decomposes and $\mathrm{CaO}$ can take part in $\mathrm{Ca}$-silicates synthesis. Quantitatively the processes taking place during ashes calcination were observed by means of chemical (Tables 2 and 3) and mineralogical (Table 4) analysis. Water (WW) and acid (IW) washing of FA-UT is sufficient for chloride (mainly as $\mathrm{KCl}$ and $\mathrm{NaCl}$ ) removal, while sulfate removal negligible due to limited solubility of various calcium sulfate forms (gypsum, basanite, anhydrite). Due to the 
dissolution of chlorides, content of other (insoluble) matters, is relatively increased. Thermally treated ashes FA-WW-TT and FA-IW-TT are featured by significant reduction of $\mathrm{SO}_{3}$ content while being calcined at $1000^{\circ} \mathrm{C}$.

Content of amorphous phase in ash is of importance when it is intended to be used Supplementary Cementitious Material because only amorphous portion can take part in hydration process and thus contribute to setting of material. FA-UT contains $43 \%$ of amorphous matter, unfortunately thermal treatment - with slow cooling - caused reduction of amorphous portion content and increase of feldspars and other silicates content.

Chemical fraction of heavy metals in treated ashes was mentioned in Table 3 was also performed by XRF. However, the treated ashes were proposed to be used as SCM, the efficient binding of the present heavy metals was subsequently ensured by cementitious environment itself. At the highest temperature we succeeded to almost remove the volatile $\mathrm{Pb}$, which is most hazardous heavy metal for the environment. On finding minimum chloride and lead fraction results at $1000^{\circ} \mathrm{C}$ we select the same sample for further studies. These heavy metals immobilizing of MSWI fly ash-cement matrixes could be more reliable in the factual environment. Therefore, the solidification property of cement on heavy metals in MSWI fly ash is favourable. Furthermore study of the immobilization/stabilization mechanism of cement on all types of heavy metals in MSWI fly ash is needed.

Table 3: Chemical Fraction of heavy metals treated fly ashes $(\mathrm{mg} / \mathrm{kg})$.

\begin{tabular}{|c|c|c|c|c|c|c|c|c|c|c|c|}
\hline & FA-UT & \multicolumn{5}{|c|}{ FA-IW-TT } & \multicolumn{5}{|c|}{ FA-WW-TT } \\
\hline & & \multicolumn{5}{|c|}{ Temp. $\left({ }^{\circ} \mathrm{C}\right)$} & \multicolumn{5}{|c|}{ Temp. $\left({ }^{\circ} \mathrm{C}\right)$} \\
\hline & & 200 & 400 & 600 & 800 & 1000 & 200 & 400 & 600 & 800 & 1000 \\
\hline As & $\mathrm{BDL}$ & BDL & $\mathrm{BDL}$ & BDL & 27 & 31 & BDL & $\mathrm{BDL}$ & 11 & 34 & 37 \\
\hline $\mathrm{Ba}$ & 317 & 354 & 308 & 302 & 317 & 377 & 394 & 415 & 431 & 390 & 464 \\
\hline $\mathrm{Cd}$ & 62 & BDL & BDL & BDL & BDL & BDL & 98 & 99 & 91 & 32 & BDL \\
\hline Co & BDL & BDL & 8 & BDL & 6 & BDL & BDL & 11 & 9 & BDL & 14 \\
\hline $\mathrm{Cr}$ & 131 & 110 & 119 & 123 & 127 & 147 & 161 & 167 & 168 & 150 & 134 \\
\hline $\mathrm{Cu}$ & 204 & 188 & 198 & 190 & 206 & 215 & 306 & 297 & 290 & 212 & 226 \\
\hline $\mathrm{Mn}$ & 266 & 210 & 212 & 196 & 216 & 322 & 343 & 353 & 348 & 374 & 415 \\
\hline Mo & BDL & BDL & $\mathrm{BDL}$ & 3 & BDL & BDL & BDL & BDL & BDL & BDL & BDL \\
\hline $\mathrm{Ni}$ & 17 & 20 & 17 & 19 & 21 & 31 & 13 & 16 & 16 & 8 & 23 \\
\hline $\mathrm{Pb}$ & 998 & 889 & 942 & 1107 & 1187 & 109 & 1422 & 1285 & 1126 & 183 & 22 \\
\hline $\mathrm{Sb}$ & 218 & 575 & 531 & 500 & 550 & 748 & 343 & 358 & 360 & 378 & 448 \\
\hline $\mathrm{Sn}$ & 302 & 490 & 455 & 433 & 458 & 685 & 452 & 490 & 497 & 532 & 590 \\
\hline V & 22 & 21 & 18 & 18 & 19 & 28 & 24 & 25 & 24 & 27 & 31 \\
\hline $\mathrm{Zn}$ & 5912 & 3133 & 2824 & 3052 & 3036 & 5270 & 9349 & 9152 & 9110 & 9013 & 9454 \\
\hline
\end{tabular}


Table 4: $\quad$ Mineralogical composition of ashes (wt. \%).

\begin{tabular}{|l|l|c|c|c|c|c|}
\hline & & FA-UT & FA-IW & FA-WW & FA-IW-TT & FA-WW-TT \\
\hline Amorphous & - & 43.0 & 50.8 & 40.0 & 27.4 & 31.9 \\
\hline Calcite & $\mathrm{CaCO}_{3}$ & 6.0 & - & 11.1 & - & 0.8 \\
\hline Quartz & $\mathrm{SiO} 2$ & 8.5 & 7.4 & 8.0 & 7 & 3.7 \\
\hline Halite & $\mathrm{NaCl}$ & 3.2 & - & 1.9 & - & - \\
\hline Sylvite & $\mathrm{KCl}$ & 2.3 & - & 1.7 & - & - \\
\hline Anorthite & $\mathrm{Ca}-\mathrm{feldspar}$ & 11.7 & - & - & - & 5.0 \\
\hline Albite & $\mathrm{Na-feldspar}$ & - & - & - & 6.7 & - \\
\hline Bytownite & $\mathrm{Ca}, \mathrm{Na}_{-} \mathrm{feldspar}$ & - & - & - & 7.8 & - \\
\hline Diopside & $\mathrm{CaMgSi} \mathrm{O}_{6}$ & - & - & - & 15.9 & 8.3 \\
\hline Akermanite & $\mathrm{Ca}_{2} \mathrm{MgSi}_{2} \mathrm{O}_{7}$ & - & 4.4 & - & - & 34.0 \\
\hline Gehlenite & $\mathrm{Ca}_{2} \mathrm{Al}_{2} \mathrm{SiO}_{7}$ & 10.8 & - & 11.6 & - & - \\
\hline Muscovite & $\mathrm{mica}$ & 2.3 & - & - & - & - \\
\hline Anhydrite & $\mathrm{CaSO}_{4}$ & 7.0 & - & 17.9 & 31.2 & 6.4 \\
\hline Bassanite & $\mathrm{CaSO}_{4} \cdot 0.5\left(\mathrm{H}_{2} \mathrm{O}\right)$ & 3.8 & 28.8 & - & - & - \\
\hline \begin{tabular}{l} 
Gypsum \\
\hline Hydroxylapatit
\end{tabular} & $\mathrm{CaSO}_{4} \cdot 2\left(\mathrm{Ca}_{2} \mathrm{O}\right)$ & - & 8.4 & - & & \\
\hline & & - & - & - & 2.5 & 8.4 \\
\hline
\end{tabular}

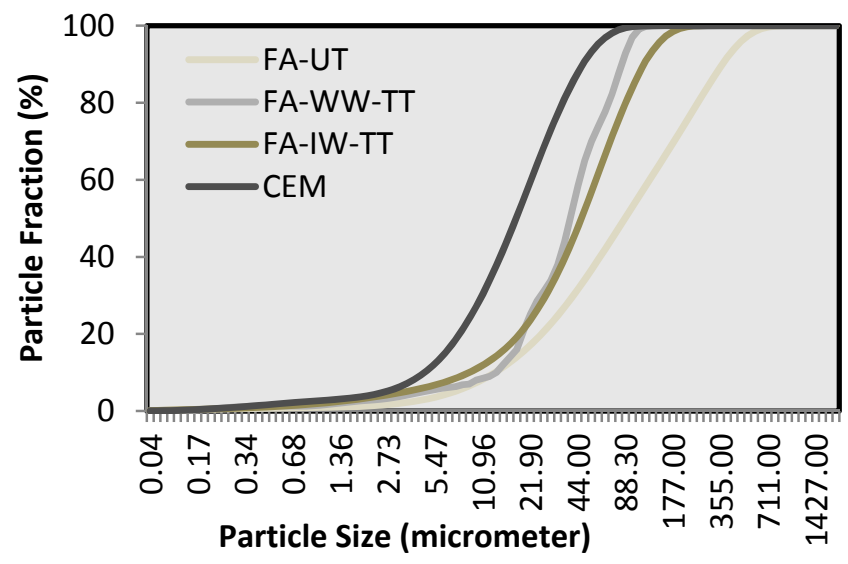

Figure 2: $\quad$ Particle size analysis of treated and untreated ashes with cement.

Thermal treatment of ashes leads to refinement of ash particles (Fig. 2) as a result of disintegration of chlorides which behave as a glue of larger particles agglomerates present in FA-UT. The retroaction of thermal treatment on particle 
size distribution was examined by grading analysis. The non-additive thermally treated ash particles just minor particles refinement compared to FA-UT. However the treated ashes particles were larger than particles of Portland cement (PC) and its size was close to standard requirement on pozzolanic admixture (remains on $45 \mu \mathrm{m}$ sieve lower than $40 \%$ ).

The compressive and bending strength test was applied on mortars prepared by substitution of untreated and treated ashes to observe impact of substitution. The possible ability of ashes to replace Portland cement (PC) was checked by help of mortars, where ashes were dosed as pozzolanic admixture. On comparing the results (Fig. 3) of both thermally treated samples; thermal treatment work for sample FA-WW-TT gives outstanding results, shows higher strength in terms of compressive strength compare to control sample at $10 \%$ substitution of PC, may be due to total removal of chlorides. However, at $20 \%$ and $30 \%$ replacements of PC also quite acceptable strength decreases slightly ( $25 \%)$, on other hand FAIW-TT and FA-UT samples fails to show any impressive remarks at any substitution; results continue decreases on further substitutions. The results comes from bending strength analysis (Fig. 4) are in agreement with compressive strength. The bending strength of mortar with sample FA-WW-TT initially decreases slightly $(0.29 \mathrm{MPa}$ i.e. $\sim 8 \%)$ in $10 \%$ of substitution, while after further substitution $20 \%$ and $30 \%$ results come with the same strength like the bending strength of the control sample.

After finding significant results of bending and compressive strength analysis, especially for FA-WW-TT sample, further studies with evaluation have been done on the basis of setting time of mortar on comparing with untreated Fly ash (FA- UT). FA-UT showed highly negative influence on initial and final setting time of fresh cement paste (Fig. 5). FA-UT takes more than 10 hours in the final setting.

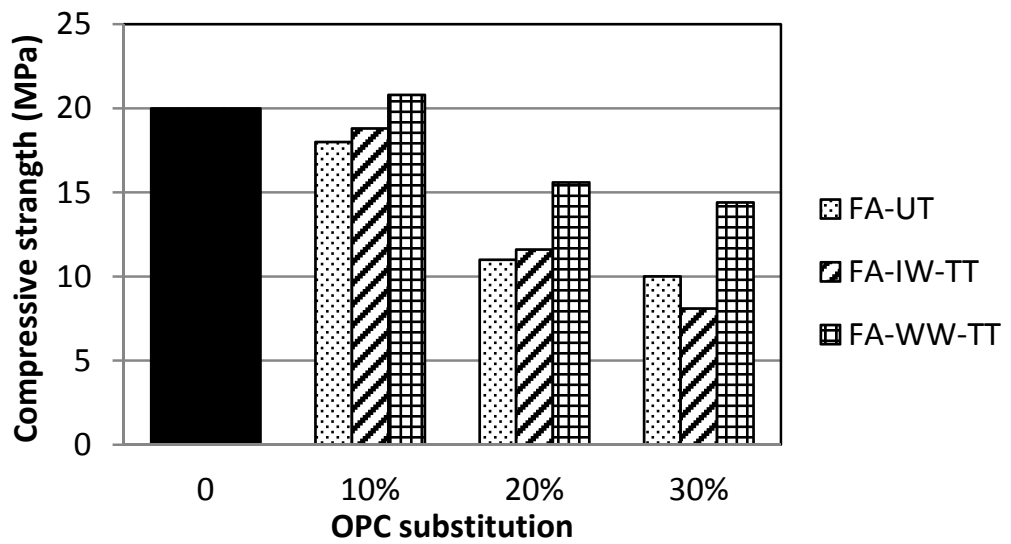

Figure 3: Influence of OPC substitution on compressive strength of mortars. 


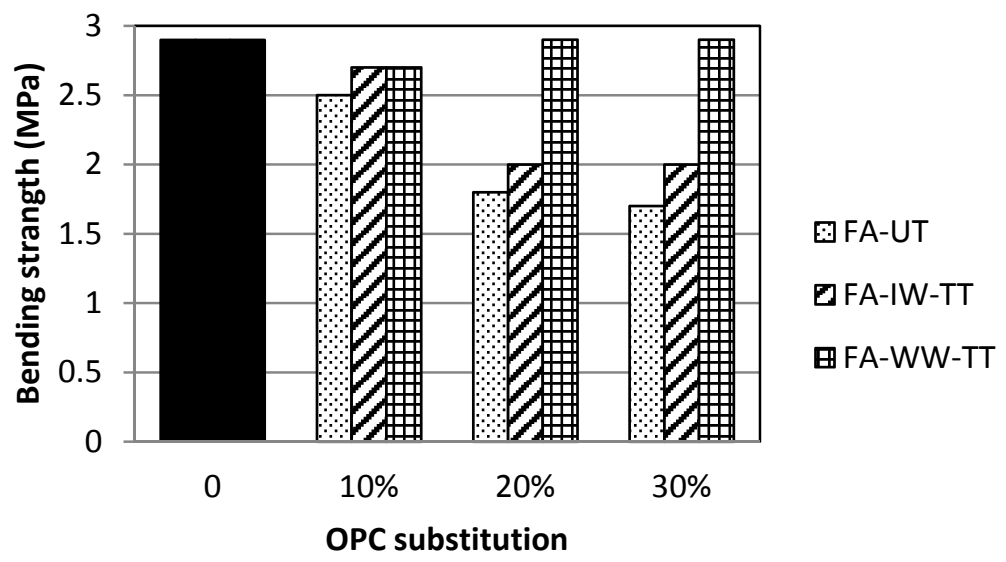

Figure 4: Bending strength of mortars containing treated ashes as SCM.

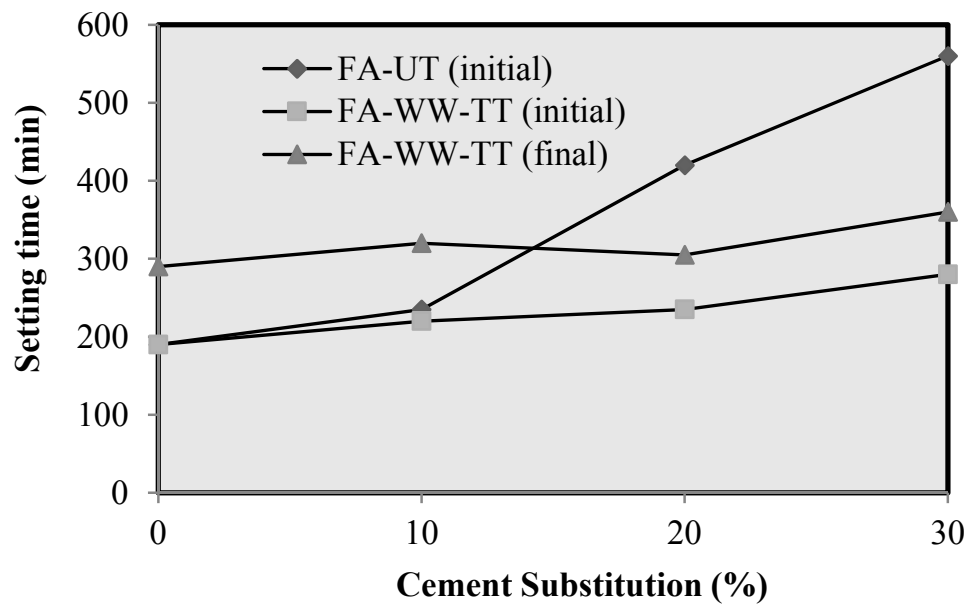

Figure 5: Comparison of setting time between FA-UT and FA-WW-TT.

On the contrary this thermally treated sample FA-WW-TT improved remarkably in their parameters; the paste with cement substitution up to $30 \%$ got set faster than the control paste. The reason was probably the reduction of chlorides content on combined water and thermal treatment decline from $11.2 \%$ to $0.007 \%$. FA-IW-TT sample also gives better results (fig. 6) to decrease the setting time with compare to untreated ash. Setting time initially increasing with $10 \%$ of substitution and on further substitution of $20 \%$ and $30 \%$ it's got success to decrease the setting time. 


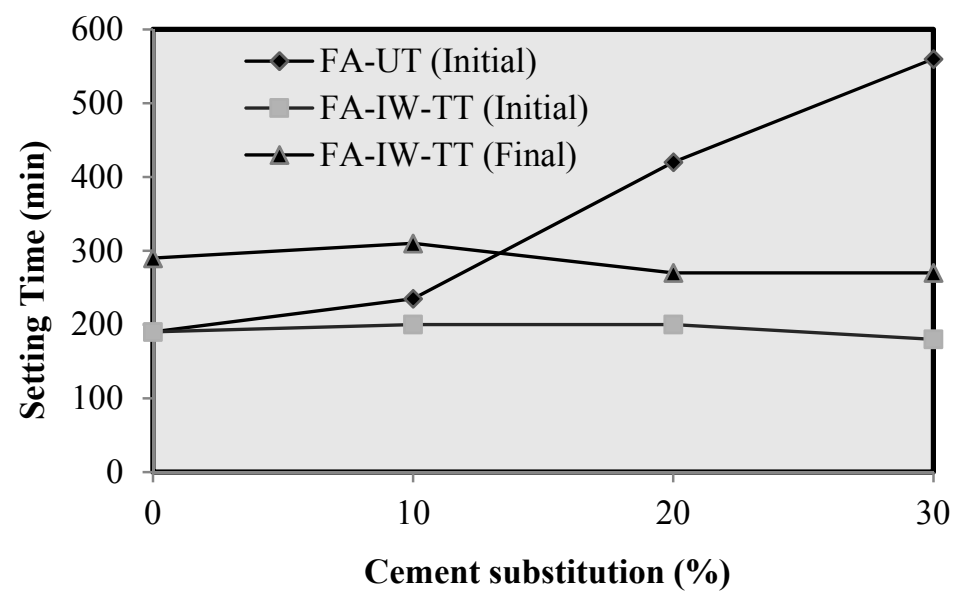

Figure 6: Comparison of setting time between FA-UT and FA-IW-TT.

\section{Conclusions}

Chemical and physical characterization of thermally treated fly ash from a modern MSWI facility was performed from the perspective of its possible utilization as pozzolanic admixture. Influence of this treatment performance of MSWI fly ash as SCM was tested. The best ability to substitute PC showed water washed fly ash treated at $1000^{\circ} \mathrm{C}$. The compressive strength of mortar with this ash as SCM was reduced just moderately. Thermally treated ash had reduced chloride content in ash and also helpful to remove hazardous heavy metal $(\mathrm{Pb})$ content. Unfortunately the thermal treatment does not solve the high sulfates' content completely; only the recrystallization to larger crystals is taking place what means a long-time durability risk.

\section{Acknowledgements}

This publication was supported by the European Social Fund within the framework of realizing the project "Support of inter-sectoral mobility and quality enhancement of research teams at Czech Technical University in Prague, CZ.1.07/2.3.00/30.0034" and by the European Union "OP RDI project No. CZ.1.05/2.1.00/03.0091 - University Centre for Energy Efficient Buildings".

\section{References}

[1] Liu, Y. S., Liu, Y. S., Novel incineration technology integrated with drying, pyrolysis, gasification and combustion of MSW and ashes vitrification. Environ. Sci. Technol., 39, pp. 3855-3863, 2005. 
[2] Stehlik, P., Contribution to advances in waste-to-energy technologies. $J$. Clean. Prod., 17, pp. 919-931, 2009.

[3] Finnveden, G., Johansson, J., Lind, P., Moberg, A., Life cycle assessment of energy from solid waste-part 1: general methodology and results. $J$. Clean. Prod., 13, pp. 213-229, 2005.

[4] Shin, K. J., Chang, Y. S., Characterization of polychlorinated dibenzo-pdioxins, dibenzofurans, biphenyls, and heavy metals in fly ash produced from Korean municipal solid waste incinerators. Chemosphere, 38, pp. 2655-2666, 1999.

[5] Cheng, H. F., Hu, Y.N., Municipal solid waste (MSW) as a renewable source of energy: current and future practices in China. Bioresour. Technol., 101, pp. 3816-3824, 2010.

[6] Council directive 1999/31/EC of 26 April 1999 on the landfill of waste. Official Journal of the European Communities, 16/7/1999, L182/1-19.

[7] Maria, I., Xavier, Q., Alejandro, J., Enric, V., Angel, L. S., Comparison between laboratory and field leachability of MSWI bottom ash as a road material. Sci. Total Environ. 389, pp. 10-19, 2008.

[8] Schreurs, J. P. G. M., Van der sloot, H. A., Hendriks, Ch., Verification of laboratory-field leaching behavior of coal fly ash and MSWI bottom ash as a road base material, Waste Manage., 20, pp. 193-201, 2000.

[9] Francois, D., Criado, C., Monitoring of leachate at a test road using treated fly ash from municipal solid waste incinerator. J Hazard Mater. B., 139, pp. 543-549, 2007.

[10] Auer, P. O., Eichler, B., Ludwig, C., Stucki, S., Wochele, J., Recycling heavy metals by the method of fractionated condensation. In: 4th World Congress: Recovery, Recycling, Re-integration. Geneve, 4, pp. 328-333, 1999.

[11] Yang, G., Tsai, C., A study on heavy metal extractability and subsequent recovery by electrolysis for a municipal incinerator fly ash. J Hazard Mater., 58, pp. 103-120, 1998.

[12] Katsuura, H., Inoue, T., Hiraoka, M., Sakai, S., Full-scale plant study on fly ash treatment by the acid extraction process. Waste Manage., 16, pp. 491-499, 1996.

[13] Derie, R., A new way to stabilise fly ash from municipal incinerators, Waste Manage., 16, pp. 711-716, 1996.

[14] Lundtorp, K., Jensen, D. L., Sørensen, M. A., Mogensen, E. P. B., Christensen, T. H., Stabilization of APC-residues with FeSO4. In: Proceedings Sardinia 99, 7th International Landfill Symposium, 1, pp. 549-556, 1999.

[15] Sakai, S., Hiraoka, M., Municipal solid waste incinerator residue recycling by thermal processes. Waste Manage., 20, pp. 249-258, 2000.

[16] Mangialardi T, Sintering of MSW fly ash for reuse as a concrete aggregate. J Hazard Mater., 87, pp. 225-239, 2001.

[17] Bernardo E., Bonomo E., Dattoli A, Optimisation of sintered glassceramics from an industrial waste glass. Ceram Int. 36, pp. 1675-1680, 2010 . 
[18] Rawlings, R. D., Wu, J. P., Boccaccini, A. R., Glass-ceramics: their production from wastes-a review. J Mater Sci., 41, pp. 733-761, 2006.

[19] Barbieri, L., Lancellotti, I., Incinerator waste as secondary raw material: examples of applications in glasses, glass-ceramics and ceramics. Geol Soc Spec Publ., 236, pp. 423-433, 2004.

[20] Lam, C. H. K., Barford, J. P. and McKay, G., Utilization of municipal solid waste incineration ash in Portland cement clinker, Clean Technol Environ Policy, 13(4), pp. 607-615, 2011.

[21] Xue, Y. J., Hou, H. B., Zhu, S. J. and Zha, J., Utilization of municipal solid waste incineration ash in stone mastic asphalt mixture: Pavement performance and environmental impact, J Constr Building Mater., 23(2), pp. 989-996, 2009.

[22] Chu, T. C., Wang, K. S., Lin, K. L., Chien, C. C., Chen, J. H., Synthesis of waste-derived glass-ceramics from MSWI fly ash and EAF dust: kinetics of nucleation and crystallization, Environ Prog Sustain Energy. doi:10.1002/ep.11647.

[23] Chaowasakoo, T., Sombatsompop, N., Mechanical and morphological properties of fly ash/epoxy composites using conventional thermal and microwave curing methods. Compos Sci Technol., 67, pp. 2282-2291, 2007.

[24] Eighmy, T. T., Eusden, J. D., Krzanowski, J. E., Dominggo, D. S., Stampfli, D., Martin, J. R., Comprehensive approach toward understanding element speciation and leaching behaviour in municipal solid waste incineration electrostatic precipitator ash. Environ. Sci. Technol., 29, pp. 629-646, 1995. 